\title{
Coal bursts in the deep longwall mines of the United States
}

\author{
Christopher Mark ${ }^{1}$
}

Received: 27 September 2015/Revised: 31 October 2015/Accepted: 10 November 2015/Published online: 30 January 2016

(C) The Author(s) 2016. This article is published with open access at Springerlink.com

\begin{abstract}
Coal bursts involve the sudden, violent ejection of coal or rock into the mine workings. They are a particular hazard because they typically occur without warning. During the past 2 years three US coal miners were killed in two coal bursts, following a 6-year period during which there were zero burst fatalities. This paper puts the US experience in the context of worldwide research into coal bursts. It focuses on two major longwall mining coalfields which have struggled with bursts for decades. The Utah experience displays many of the "classic" burst characteristics, including deep cover, strong roof and floor rock, and a direct association between bursts and mining activity. In Colorado, the longwalls of the North Fork Valley (NFV) also work at great depth, but their roof and floor strengths are moderate, and most bursts have occurred during entry development or in headgates, bleeders, or other outby locations. The NFV bursts also are more likely to be associated with geologic structures and large magnitude seismic events. The paper provides a detailed case history to illustrate the experience in each of these coalfields. The paper closes with a brief discussion of how US longwalls have managed the burst risk.
\end{abstract}

Keywords Underground mining $\cdot$ Coal $\cdot$ Burst $\cdot$ Longwall $\cdot$ Strata control

\section{Introduction}

Coal bursts involve the sudden, violent ejection of coal or rock into the mine workings (Figs. 1,2). They are almost always accompanied by a loud noise, like an explosion, and ground vibration. Bursts are a particular hazard for miners because they typically occur without warning. Despite decades of research, the sources and mechanics of bursts are imperfectly understood, and the means to predict and control them remain elusive.

High stress is a universal feature of burst-prone conditions. The overburden depth is responsible for the overall

Christopher Mark

mark.christopher@dol.gov

1 U.S. Mine Safety and Health Administration, Pittsburgh, PA, USA level of stress, but pillar design, multiple seam interactions, and/or mining activity can concentrate stresses in distinct locations.

Geologic factors also contribute. The presence of strong, massive sandstone near the seam has often been noted where bursts have occurred (Bräuner 1994; Maleki 1995; Iannacchione and Zelanko 1995; Agapito and Goodrich 2000). In the Utah coalfields of the western US, for example, miners refer to "bump sandwich" geology where the coal seam is slotted between massive sandstone roof and floor. In Germany, a study that compared rock cores from 35 areas that experienced bursts with cores from 400 burst-free areas found that the burst risk was significant when there was either a $4.5-\mathrm{m}$ thick "package" of strong sandstone in the first $10 \mathrm{~m}$ above the mining horizon, or a 2-m-thick "package" within the first $4.5 \mathrm{~m}$ of the floor (Baltz and Hucke 2008).

Near seam geology does not wholly determine the burst risk, however. Other geologic factors that have been identified as contributing to a heightened burst risk include the following: 

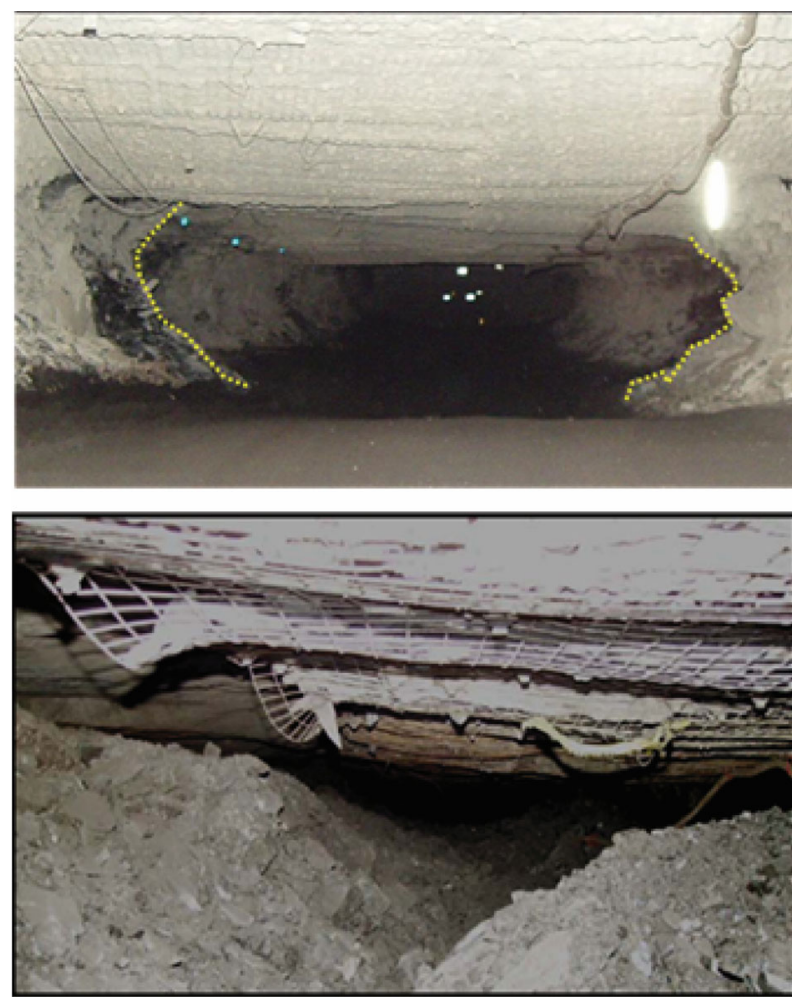

Fig. 1 Effect of a coal burst on roadway (the top shows the roadway before the burst, and the bottom is after the burst)

(1) Rapid changes in the depth of cover (Holland 1958; Maleki 1995; Maleki et al. 1999)

(2) Sandstone channels that concentrate load (Hoelle 2008; Agapito and Goodrich 2000; Maleki et al. 2011)

(3) Seam rolling and pitching (Iannacchione and Zelanko 1995; Maleki et al. 2011)

(4) Faults (Holland 1958; Holub 1997; Agapito and Goodrich 2000; Alber et al. 2008; Swanson et al. 2008)

As long ago as the early 1930s, coal bursts were classified into two types according to their apparent cause (Rice 1935). "Pressure bursts" were thought to originate in the seam itself and were associated with high stress and direct mining activity. Typical pressure bursts occur while a continuous miner is extracting a pillar or a longwall shearer is cutting the tailgate corner of the face.

"Shock bursts", on the other hand, were thought to be caused by "the breaking of a thick, massive, rigid strata at a considerable distance above the coal bed, causing a great, hammerlike blow to be given to the immediate roof of the mine opening, (transmitting) a shock wave to the coal pillar or pillars" (Rice 1935). These events could occur on off shifts, outby the face, in bleeder pillars, or other unexpected times and locations. Today, we understand that the sudden, dynamic failure in the overlying (or underlying) strata releases elastic energy in the form of seismic waves. The failures include
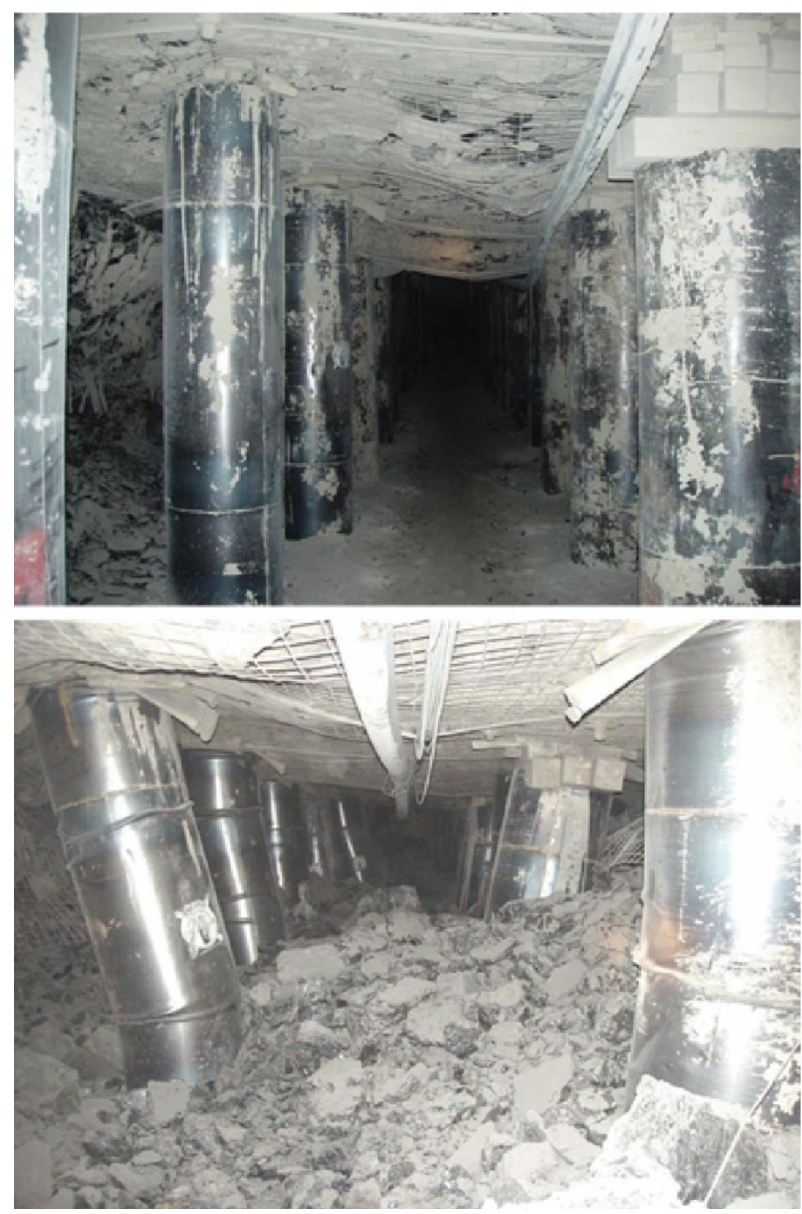

Fig. 2 Effect of a coal burst on a longwall tailgate

sudden downward movements of the rock above the workedout areas, shear slip motion on faults or fractures in the overburden, or some combination of these two mechanisms (Pankow et al. 2008). Shear slip motion can occur on newlycreated fractures, or on reactivated pre-existing faults (Swanson et al. 2008; Alber et al. 2008). The seismic energy released by such events can cause damage both underground and on the surface.

The "shock burst" phenomenon is well known internationally, both in hard rock mines and in burst-prone coalfields. For several decades, the deep South African gold mines have been aware that mining too near a fault can trigger a major rock burst. Researchers at the Australian Centre for Geomechanics (ACG) have developed a quantitative rock burst risk control method that includes the following elements (Potvin 2009):

(1) Identifying sources of seismic energy, including faults and other geologic or mining structures

(2) Estimating the maximum likely seismic energy release from each individual seismic source

(3) Assessing the largest potential ground motion (peak particle velocity) in the mine as a function of the 
magnitude of the event and the distance of the mine workings from the event

(4) Assessing the potential damage to the mine resulting from the ground motions, and modifying the mine plan as necessary to control the risk

The ACG approach relies on the availability of seismic source locations obtained from high quality, three-dimensional seismic monitoring systems. Such systems have been employed in some burst-prone European coalfields. In Czechoslovakia, for example, researchers have been able to study the relationship between the magnitude and location of seismic events and the extent of damage underground. In one instance, extensive damage resulted from a seismic magnitude $(M)$ event, where $M=2.8$, that was located more than $100 \mathrm{~m}$ away from the workings (Holub et al. 2011). On the other hand, even very large events may have little impact on the mine if they occur well above the workings. During one 5-year period in Poland, there were 15 large mining-induced events with $M$ ranging from 2.2 to 4.0 (Mutke and Stec 1997). Only 6 of these had any significant effect underground. Seam level "mining tremors", on the other hand, are often too small to register on a regional seismic network, but they can result in serious injury if a miner is in the vicinity (Mutke and Stec 1997).

It is evident that a wide range of causes can result in coal bursts. The volume of coal involved in bursts also covers a wide spectrum, from a few chunks of coal up to a whole array of pillars. The common link between all these events appears to be the failure mechanism of the coal itself. In general, coal is able to carry high vertical stress (or more precisely, maximum principal stress (sigma 1)) only when it also carries large confining stresses (or minimum principal stress (sigma 3 )). If the vertical load is increased under these conditions, failure usually takes the form of non-violent yielding. A coal burst, on the other hand, apparently results when the confining stress is suddenly reduced. Research by Babcock and Bickel (1984) indicated that a wide variety of coals can be induced to fail violently by this "loss of confinement" mechanism. The loss of confinement can either be the result of mining activity, or of the ground shaking that accompanies an off-seam seismic energy release (a mining-induced earthquake).

One factor that does not seem to be strongly correlated with bump proneness is the character of the coal. Iannacchione and Zelanko (1995) noted that bursts have occurred in at least 25 different US coalbeds, varying from strong, blocky seams to very friable ones like the Pocahontas No. 3 and No. 4. Extensive German laboratory studies using large-scale specimens have also concluded that nearly all bituminous coals can burst. In these experiments, coal seams ranging in unconfined, compressive strength from $5 \mathrm{MPa}$ to $50 \mathrm{MPa}$ have all been shown to be burst-prone (Bräuner 1994).

\section{Coal bursts in the US}

The long history of coal bursts in the US has been welldocumented. Iannacchione and Zelanko (1995) analyzed a database of 172 bursts that had occurred between 1936 and 1993. These bursts had resulted in a total of 87 fatalities and 163 injuries. Reflecting the mining technology in use during this period, $61 \%$ of the events occurred during pillar recovery operations, and $25 \%$ during longwall mining. The remaining $14 \%$ occurred during development.

Three main coalfields have accounted for the vast majority of bursts. Iannacchione and Zelanko reported that $65 \%$ of the bursts in their database occurred in the Central Appalachian coalfields of West Virginia, Virginia, and Kentucky. Most of the rest occurred in Colorado (17 \%) or Utah $(15 \%)$. Bursts occurred at more than 50 different mines during this period. Iannacchione and Zelanko found that nearly all bursts occurred at depths greater than $300 \mathrm{~m}$, and most were greater than $400 \mathrm{~m}$.

A database of coal bursts that occurred during the period 1994-2013 was recently developed. It includes a total of 140 events that were reported to MSHA. ${ }^{1}$ An additional 13 events involved roof "thumps", but since they did not result in violent ejection of coal or rock they were not included in the total. ${ }^{2}$

Four of the 140 events in the new database resulted in a total of five fatalities, two on longwalls, and three during two pillar recovery events. Note that the Crandall Canyon mine disaster which claimed six lives is not included in the database. That event was unique and can be best described as a catastrophic, mine-wide, pillar system failure. The area that collapsed at Crandall Canyon was enormous, encompassing 20 rows of pillars over approximately one square kilometer. It has more in common with the massive pillar collapses described by Mark et al. (1997) and Zipf (1992) than with a typical coal burst. $^{3}$

Figure 3 shows that since the 1980's there has been a generally declining trend in the number of reported bursts.

\footnotetext{
${ }^{1}$ In the US, coal mines must report to MSHA any "coal or rock outburst that causes withdrawal of miners or which disrupts regular mining activity for more than $1 \mathrm{~h}$ " (Code of Federal Regulations, Title 30, Part 50.2). However, there is no special data field which identifies an accident report as a burst. The burst database employed in the present study was constructed by searching MSHA accident report narratives for terms such as "burst", "bump" and "bounce". Only those incidents where the narrative clearly indicated that a burst had occurred were retained in the database.

2 An example of this type of event is given by the following narrative, which describes an event that occurred during pillar recovery at a West Virginia mine in 1996: "Employee was helping set timbers on pillar line when the top bumped, rolling a coal rib onto his lower back."

3 The second event that occurred at Crandall Canyon and killed three rescuers was a pillar burst, but it has also been excluded because it occurred during the unique circumstances of a mine rescue.
} 


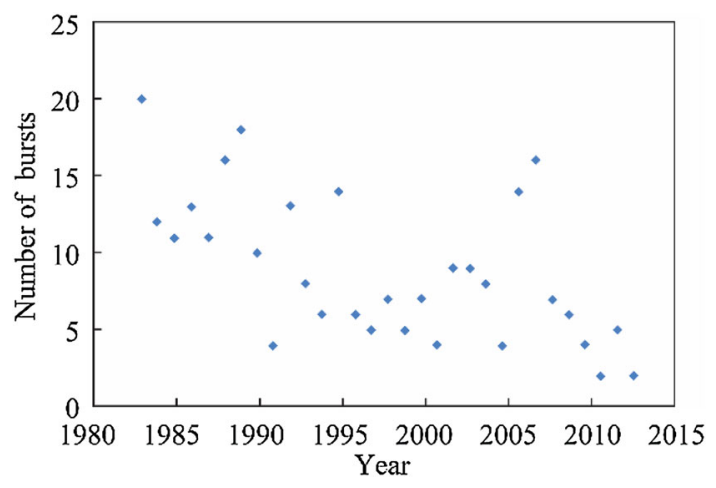

Fig. 3 Number of coal bursts reported to MSHA, 1983-2013

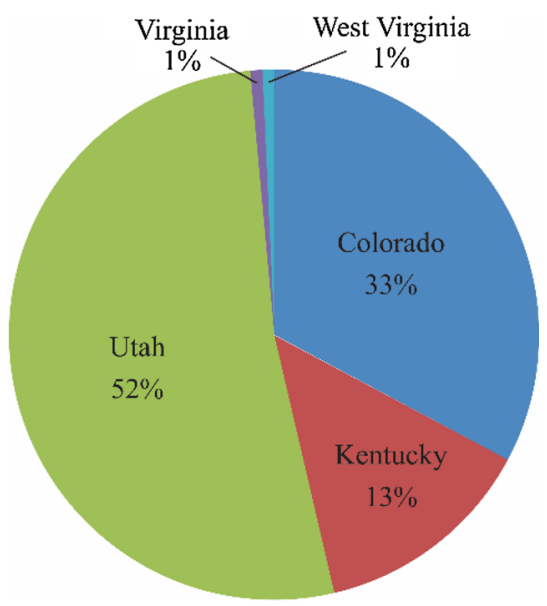

Fig. 4 Coal bursts reported to MSHA, by state, 1994-2013

Some of this improvement can be attributed to changes in mining methods and geologic environments. Longwall mining has largely replaced pillar recovery in the western US, and much less coal is being mined from the burst prone Pocahontas coalfields of Virginia and West Virginia. On the other hand, longwalls work deeper seams today than they did 30 years ago, and multiple seam interactions are much more prevalent. Therefore it seems evident that much of the improvement must be due to the better mining practices, some of which will be discussed further on.

Figure 4 shows that during the past 20 years Utah mines have accounted for the largest number of bursts, followed by Colorado. Virginia and West Virginia only recorded one burst each, though together those two states had accounted for $54 \%$ of the bursts during the earlier period analyzed by Iannacchione and Zelanko (1995). Unfortunately, in 2014 a coal burst killed two West Virginia miners. Most coal mining in Central Appalachia is conducted by room-andpillar methods, though the experience of one burst prone longwall has been described in detail by Hoelle (2008).

Figure 5 shows that $41 \%$ of the bursts during the past 20 years have occurred on the longwall face. Another $20 \%$

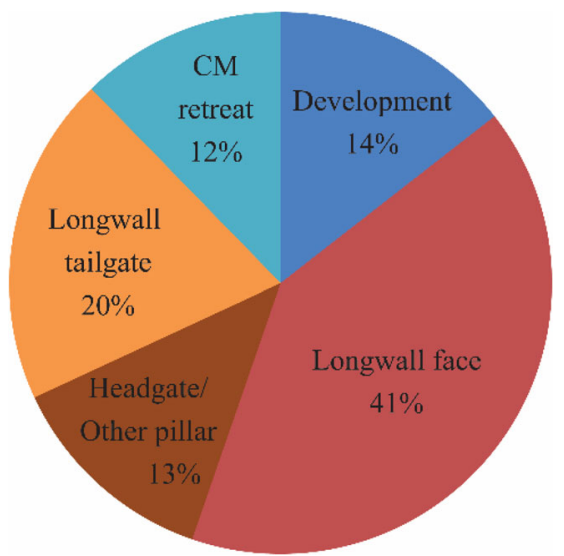

Fig. 5 Coal bursts reported to MSHA, by location in the mine, 1994-2013

affected the tailgate entry at the corner of the longwall face, and $12 \%$ occurred during retreat mining. All of these locations are subject to very high stresses, and they are directly affected by mining activity, and so might be considered likely locations for bursts. On the other hand, $14 \%$ of the bursts occurred during entry development, and another $13 \%$ affected pillars in the headgate, bleeder, or other outby locations.

There are also some significant regional trends. In Utah, $76 \%$ of the total 68 events occurred on the longwall face, and another $10 \%$ occurred either in the longwall tailgate or during pillar recovery. Similarly, in Central Appalachia, $81 \%$ of the 21 reported bursts occurred on the longwall face, tailgate, or pillar line. In Colorado, on the other hand, nearly half of the bursts occurred during entry development or in the headgate, bleeder, or other outby location. And although 40 of the 46 Colorado events took place in longwall mines, only two occurred on a longwall face.

\subsection{Utah experience}

The coalfields of Utah are located in the mountainous central region of the state (Fig. 6). The minable coal seams crop out of plateau escarpments, giving rise to rapid increases in cover depths. Typical mining depths of 450-900 m are among the very deepest in the US. The strata are characterized by numerous thick and strong sandstone and siltstone beds, with rock strengths reaching $130 \mathrm{MPa}$.

The first coal bursts were recorded in Utah almost 100 years ago. They were typically associated with pillar recovery under deep cover. However, Peperakis (1958) noted that severe bumps at the Sunnyside Mine in Utah had occurred in virgin development a long distance away from active workings, and were attributed to geologic faults.

Bursts were one reason why Sunnyside was one of the early longwall pioneers in the US. Through a lengthy process during which many gateroad configurations were 


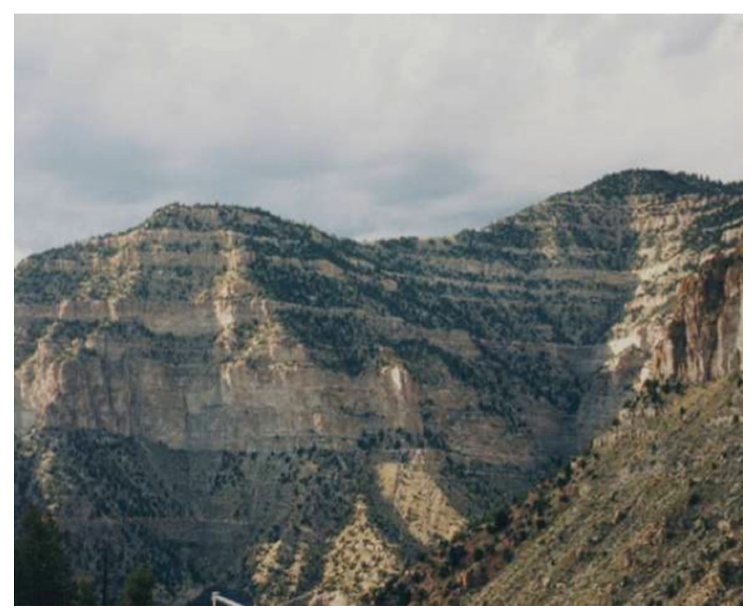

Fig. 6 Mountainous terrain in the Utah coalfields. Note the thick, cliff-forming sandstone units

trialed, Sunnyside engineers developed a two-entry, yield pillar system that virtually eliminated pillar bursts. The yield pillars were typically $9 \mathrm{~m}$ wide in $2.5-3 \mathrm{~m}$ thick seams (DeMarco et al. 1995). Mining engineers also learned to avoid "critical" pillars which are too large to yield non-violently yet too small to support large abutment loads. The width-to-height ratios of such burst-prone, critical pillars normally exceeded 4 or 5 (DeMarco et al. 1995). Longwall face bursts continued to be a problem however, typically once the cover depth exceeded $450 \mathrm{~m}$.

Seismicity induced by mining operations in Utah has also been extensively studied. The University of Utah operates a regional seismic system which recorded 148 mining induced events with Local Magnitude $M_{\mathrm{L}}>2.5$, including 18 with $M_{\mathrm{L}}>3.0$, between 1978 and 2000 (Arabasz and Pechmann 2001). Of the larger events, three were judged to have shear-slip mechanisms, while 13 had possible collapse-type mechanisms. Few of these large events coincided with longwall bursts underground. The largest mining induced event ever recorded in Utah was the $M=4.2$ shear-slip event that was located $150 \mathrm{~m}$ above face of the second panel the Willow Creek mine. This event was large enough to cause rock falls that closed a railroad and major highway, but it resulted in only minor damage in the vicinity of the longwall (Ellenberger and Heasley 2000).

Case history Mine A was located in the Book Cliffs region of central Utah (MSHA 1996). The massive Kenilworth sandstone formation lies 6-12 $\mathrm{m}$ above the seam, and the strata between it and the seam includes other strong siltstones and sandstones with typical strengths of about $100 \mathrm{MPa}$. Another massive sandstone, the Aberdeen, lies directly beneath the seam. The seam dip was 6-12 degrees, so each successive panel was about $40 \mathrm{~m}$ deeper than the previous one. Some mining had been conducted in a coal seam lying approximately $85 \mathrm{~m}$ above Mine A, but there were no noticeable stress transfers.

Longwall mining began in 1995. Panels were developed $225 \mathrm{~m}$ wide in the $3 \mathrm{~m}$ thick seam. A three-entry yield pillar system, with entries on 15 by $36 \mathrm{~m}$ centers, separated the first longwall panel from the second. The cover above the tailgate of the second panel was about $480 \mathrm{~m}$.

As the second panel retreated, "bounces" consisting of sudden forceful vibrations became increasingly common on the tailgate end of the panel. Five of these events resulted in broken shearer torque shafts.

A major coal burst occurred when the panel had been retreated $225 \mathrm{~m}$. The shearer had just begun the double-cut at the tailgate that began the return pass towards the headgate. Approximately $30 \mathrm{~m}$ of the face blew out, propelling coal across the conveyor and into the shields, and causing fatal injuries to the shearer operator. Floor, roof, and rib damage from the burst was also visible for $45 \mathrm{~m}$ along the tailgate entry. This event registered $M=2.2$ on the regional seismic network (UUUS 2014).

In the wake of this incident, the remainder of the second panel was abandoned. A new tailgate was driven for the third panel, leaving the remainder of the second panel as an interpanel barrier pillar protecting the third panel tailgate from abutment loads arising from the first panel. Subsequent panels were also developed with the interpanel barrier design, leaving solid pillars up to $180 \mathrm{~m}$ wide between adjoining panels. Two independent sets of two-entry yield pillar gates were driven for each new panel.

Almost 10 years after the first fatal burst, the seventh longwall panel was being retreated at Mine A under almost $840 \mathrm{~m}$ of cover (MSHA 2006). Bounces were common along the longwall face, ranging from thumps in the roof or floor to coal being blown from the face. These events occurred all along the longwall face, but were most common near the headgate and tailgate entries. "Bounce procedures" were in place to protect the workers by limiting access to the face when the shearer was near the gate entries and specifying that shearer operators should position themselves behind the $8 \mathrm{~m}$ long deflector shields mounted above the shearer. The deflector shields were hinged off the shearer frame to be lowered or raised to accommodate mining clearance. In addition, expanded metal guards were attached to the armored face conveyor periodically along the walkway, and sheets of conveyor belting were suspended from the bottom of shield canopies along the walkway.

Despite these precautions, a fatal bounce killed a shearer operator located approximately $15 \mathrm{~m}$ from the headgate corner as the shearer was double-cutting towards the headgate (Fig. 7). The burst extended approximately $15 \mathrm{~m}$ along the face, with the largest cavity about $1 \mathrm{~m}$ deep directly in front of the victim. This event measured 


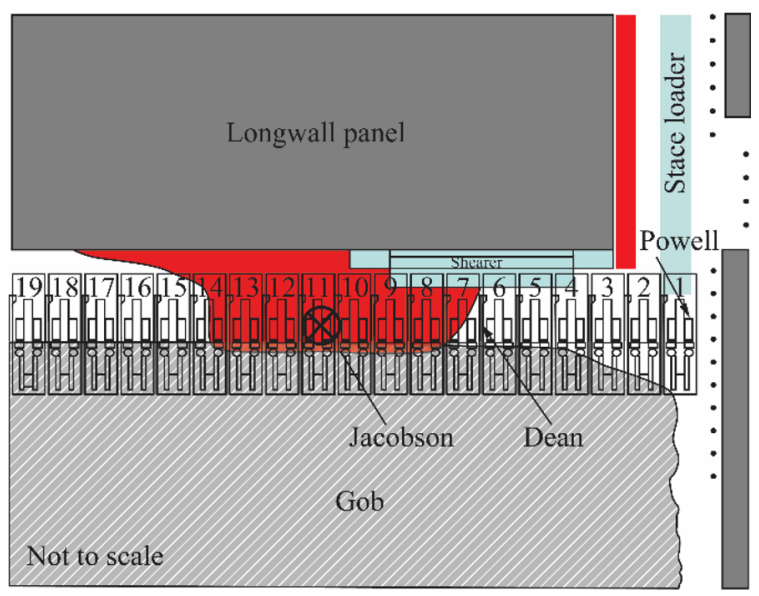

Fig. 7 Sketch of the second burst accident scene at Utah Mine A (MSHA 2006)

$M=1.2$ on the seismic network. Mine A closed not long afterward, because the burst hazard could not be effectively managed at the even greater depths above the remaining reserves.

The experience at Mine A demonstrated both the advantages and limitations of the two Utah longwall pillar design techniques. While the yield pillar system used on the first two panels typically performs well at depths up $600 \mathrm{~m}$ or so, it concentrates the load on the tailgate corner of the longwall face, and this can make it unworkable at greater depths. After the interpanel barrier method was introduced at Mine A, it was adopted at several other Utah longwalls (Gilbride and Hardy 2004). In some cases, rather than leave a full barrier, these mines elected to make midpanel moves around the area of deepest cover, thus providing a local interpanel barrier for the next panel (Maleki 2006).

The interpanel barrier effectively protects the tailgate corner from the influence of previous panels, but at greater depths the single-panel stresses on the longwall face reach the same levels as were present with abutment loads and yield pillars. This limitation led one major Utah operator to announce in 2008 that it would write off reserves at depths exceeding $900 \mathrm{~m}$ as unmineable (Foy 2008).

\subsection{Colorado experience}

While coal bursts have occurred in several different coalfields in central and western Colorado, in recent years the problems have focused on operations in the North Fork Valley (NFV) of the Gunnison River. The NFV is an area of extremely mountainous topography where drift mines can encounter depths of cover that exceed $600 \mathrm{~m}$. Past mining also gives rise to multiple seam interactions in some areas.
The geology of the NFV differs from Utah in that the immediate roof of the most common mining horizons is of weak to moderate strength. Usually composed of interbedded siltstone, fossiliferous shale, and thin layers of sandstone, Coal Mine Roof Rating (CMRR) values typically range between 40 and 60 , with typical UCS values of 50-80 MPa (Maleki et al. 2006; Stewart et al. 2006). The immediate floor usually contains a considerable thickness of coal. Massive sandstone units, with strengths exceeding $100 \mathrm{MPa}$, are typically found about $15 \mathrm{~m}$ beneath the mineable seams (Maleki et al. 2009). Faulting and joint zones are present throughout the coalfield, and active tectonism continues to occur in the region today (Swanson et al. 2008).

Case history Mine B began longwall mining in 2002 (Mark et al. 2012). In 2004, a series of three bursts occurred in the tailgate of the active longwall face as it was passing over underlying works at greater than $450 \mathrm{~m}$ of overburden. A fourth event occurred the following year in the adjacent panel tailgate in the absence of underlying workings. A fifth burst occurred 3 years later beneath some of the deepest overburden encountered up to that time $(540 \mathrm{~m})$. No multiple seam interaction was present in this instance. The pillars in this district were developed on 33 by $60 \mathrm{~m}$ centers, and maintained Analysis of Longwall Pillar Stability (ALPS) stability factor (SF) of less than 0.6.

Late in 2009, the mine began longwalling in a new district, with depths of cover that consistently exceeded $600 \mathrm{~m}$. The pillars were significantly larger than any that had been used at the mine in the past, with three entries driven on $57 \mathrm{~m}$ centers, and they maintained an ALPS SF of 1.12 (bleeder loading) even at a depth of $680 \mathrm{~m}$. The first panel (panel D-1 in Fig. 8) was extracted without serious incident, but, midway through the D-2 panel in 2011, a powerful burst that registered $M=3.1$ caused extensive pillar failure and floor heave over a 3 ha area of

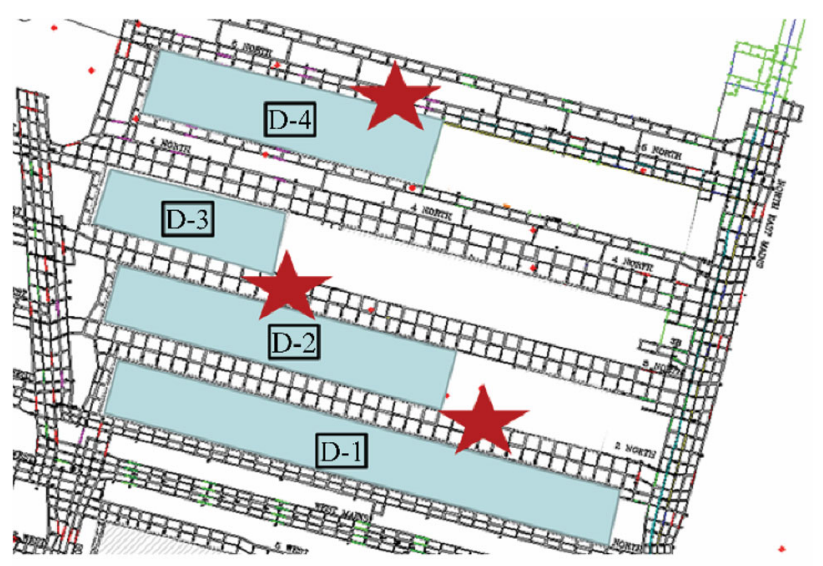

Fig. 8 Map of Colorado Case History Mine B, showing the locations of the bursts discussed in the texts (red stars) 
tailgate pillars. Ventilation was also severely affected, and the panel was abandoned.

The burst in the D-1 tailgate was centered at least $150 \mathrm{~m}$ outby the tailgate corner, so it is unlikely that front abutment stresses were a significant contributing factor. The burst did occur within the linear projection of a densely jointed and slickensided joint zone that had been identified in the mains more than $1000 \mathrm{~m}$ away several years before. It was one of a series of joint zones that were arrayed with roughly constant spacing across the mine reserve, exhibiting an approximate $\mathrm{N} 70^{\circ} \mathrm{E}$ trend.

Another of these other structural features was associated with a burst that resulted in an injury during the development of the headgate for the D-3 panel. This feature was cause for concern because it crossed the tailgate of the D-3 panel at about mid-panel. When another large tailgate burst occurred during the mining of the D-3 panel, however, it was well in by this zone. While not as destructive as the burst that occurred on the D-2 panel, it destroyed 1.6 ha of tailgate pillars and again forced the abandonment of the panel. This event was recorded as $M=3.2$.

A new gateroad was developed in order to leave an additional $75 \mathrm{~m}$ interpanel barrier to isolate the D-4 panel from the D-3 panel. Mining had advanced approximately $400 \mathrm{~m}$ in the D-4 panel, and the face was beneath almost $800 \mathrm{~m}$ of cover, when the largest burst yet, with $M=3.4$, destroyed 4 ha of headgate pillars in by the face. Ventilation was again severely affected. Several weeks later, before the face could be recovered, a heating event developed in the gob. Ultimately the face was abandoned and the mine was sealed.

Case history Mine B illustrates some of the typical key characteristics of NFV bursts, which make the area somewhat unique among burst-prone coalfields around the world:

(1) The immediate roof and floor seldom consists of strong, massive rock, but typically consists of relatively thin beds of moderate strength or even weak material.

(2) While the incidence of bursts clearly increases with depth, with almost all occurring at depths greater than $450 \mathrm{~m}$, often the bursts do not occur beneath the maximum cover in an area.

(3) Most bursts are apparently not directly triggered by coal-cutting activities, and many occur in areas of lower mining stress such as headgates or development sections.

(4) In many cases, the pillar designs were sufficiently robust that they would have been expected to provide adequate support to the overburden.

(5) The bursts often have a greater effect on the floor than they do the pillar ribs.

(6) The bursts are often associated with known geologic structures, particularly low-angle faults and zones of high-density jointing that exhibit little to no displacement.

(7) The bursts are often associated with large seismic events.

Taken together, these characteristics imply that the most significant bursts in the NFV are largely of what Rice (1935) would have called the "shock bump" variety. In other words, they appear to be driven by large seismic energy releases occurring at some distance from the coal seam, often apparently from the massive sandstones below.

\section{Management of coal bursts}

Managing the risk of coal bursts begins with an evaluation of the factors that increase the likelihood of bursts. These include the depth of cover, the presence of past mining above or below, the roof and floor geology, and the presence of faults and other geologic factors. A past history of bursts is one of the most powerful indicators of burst risk during any type of mining. Major bursts have often been preceded by smaller ones. Often these "precursors" have occurred at the same stage in the mining process as the subsequent large event (for example, in the same location on the longwall face). Also, once a mine has experienced bursts, later situations with similar geology and mining methods should also be considered high risk.

Once zones at elevated risk of bursts are identified, the next step is to determine appropriate control techniques to employ within each one. According to risk management principles, the most effective way to reduce a risk is to eliminate it entirely (Iannacchione et al. 2008). In the context of burst control, this would be achieved by not mining at all in the areas of greatest risk.

Where the risk is not great enough to indicate complete avoidance, mining may be limited to development only. For example, in a mountainous area, the main entries might be developed beneath the ridgeline where the cover is deepest.

Pillar design is the primary engineering control for minimizing the risks of pillar failure and coal bursts during retreat mining under deep cover. In longwall mines, three types of pillar design have been used to reduce the risk of coal bursts (Fig. 9). Operational techniques used by longwall mines to reduce the burst risk include reducing the depth of the web, reducing the the speed of the shearer, uni-directional cutting, and/or avoiding double cuts at the gate ends.

Administrative controls can be used to limit the exposure of miners to the areas of highest burst risk (Varley and Whyatt 2008). They can include:

(1) Allowing only the minimum number of persons required to extract the coal into the areas where coal is being mined. 
(a)

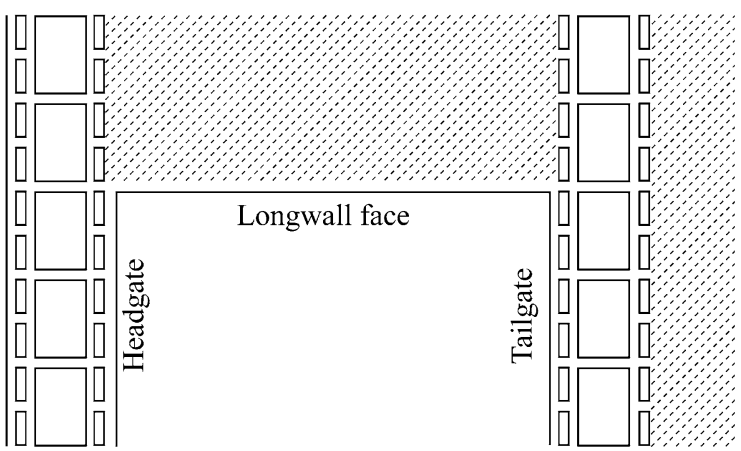

(b)

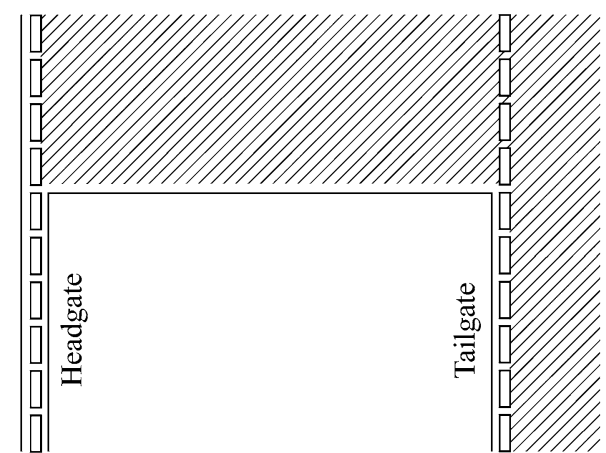

(c)

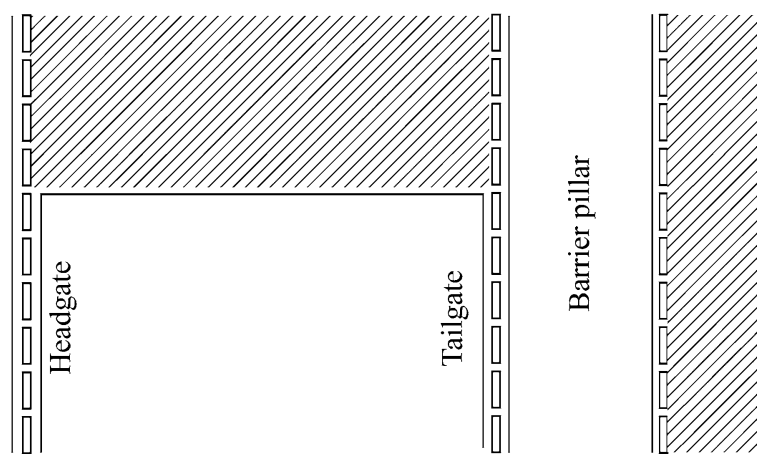

Fig. 9 Longwall pillar configurations used in the US to control coal bursts. a "Conventional" four-entry design using a large abutment pillar flanked by two smaller pillars; $\mathbf{b}$ a two-entry yield pillar design; c an inter-panel barrier design

(2) Positioning remote-control equipment operators as far from the active mining as practical (depending on radio signal range and visibility constraints).

Physical barriers can be used to protect miners from the full force of a burst event. They can be helpful against small bursts, but are likely incapable of absorbing the energy from the largest events. Examples of physical barriers that have been used on longwalls include conveyor belting secured between the shields and the face conveyor, and metal plate burst protectors installed on shearing machines. Miners can also be provided with personal protective equipment (PPE), such as helmets, face shields, or body armor, though such devices can only protect miners from small events.
The value of administrative controls, physical barriers, and PPE is also compromised if they are not correctly and consistently employed. Therefore, such techniques require worker training and constant management attention.

Destressing techniques, including drilling, water infusion, hydrofracturing, and blasting, have occasionally been used to reduce the burst risk (Varley and Whyatt 2008; Maleki et al. 2011). While some of these techniques are used routinely in German mines (Baltz and Hucke 2008), their performance in the US has been mixed. The difficulties of identifying optimum distressing times and ability to assess the effectiveness of each destressing attempt, the limited time available for face destressing (to avoid production delays) and adverse drilling conditions reduced the overall success of the efforts. Hydrofracturing is perhaps the most promising technique for modern high-production longwalls (Hoelle 2008).

Underground observations and monitoring are critical components of a burst risk management program. Mining crews should be trained to observe coal burst warning signs, particularly the occurrence of small bursts, which are often the best indication that an area is becoming more burst prone. A record-keeping system should be maintained, and management processes developed to ensure that warning signs receive appropriate responses.

\section{Conclusions}

Coal bursts remain a significant hazard for miners in the US and around the world. While coal bursts cannot be predicted in advance, the risk can be estimated through careful evaluation of those factors known to be associated with coal bursts. Understanding the different characteristics of coal bursts in specific coalfields is also critical to the risk evaluation.

Open Access This article is distributed under the terms of the Creative Commons Attribution 4.0 International License (http://crea tivecommons.org/licenses/by/4.0/), which permits unrestricted use, distribution, and reproduction in any medium, provided you give appropriate credit to the original author(s) and the source, provide a link to the Creative Commons license, and indicate if changes were made.

\section{References}

Agapito JFT, Goodrich RR (2000) Five stress factors conducive to bursts in Utah, USA, coal mines. In: Proceedings of the 19th international conference on ground control in mining. West Virginia University, Morgantown, WV, pp 93-100

Alber M, Fritschen R, Bichofff M, Meier T (2008) Rock mechanical investigations of seismic events in a deep longwall coal mine. Int J Rock Mech Min Sci 46(2):408-420 
Arabasz WJ, Pechmann JC (2001) Seismic characterization of coalmining seismicity in Utah for CTBT monitoring: report to Lawrence Livermore National Laboratory, LLNL Research Agreement No. B344836, variously paginated, 3 appendices. http://www.seis.utah.edu/Reports/lln12001/index.shtml

Babcock CO, Bickel DL (1984) Constraint: the missing variable in the coal burst problem. In: Proceedings of the 25th U.S. symposium on rock mechanics, Evanston, IL, pp 639-647

Baltz R, Hucke A (2008) Rockburst prevention in the German coal industry. In: Proceedings of the 27th international conference on ground control in mining. West Virginia University, Morgantown, WV, pp 46-50

Bräuner G (1994) Rockbursts in coal mines and their prevention. Taylor \& Francis, New York, p 152

DeMarco MJ, Koehler JR, Maleki H (1995) Gate road design considerations for mitigation of coal bumps in western U.S. longwall operations. In: Maleki H, Wopat PF, Repsher RC, Tuchman RJ (eds) Proceedings: mechanics and mitigation of violent failure in coal and hard-rock mines. U.S. Department of the Interior, Bureau of Mines, SP 01-95, Spokane, WA, pp 141-165. NTIS No. PB95211967

Ellenberger JL, Heasley KA (2000) Coal mine seismicity and bursts: historical case studies and current field activity. In: Proceedings of the 19th international conference on ground control in mining. West Virginia University, Morgantown, WV, pp 112-120

Foy P (2008) Utah's deep coal operators face heavy regulation. Associated Press news item, 28 June

Gilbride LJ, Hardy MP (2004) Interpanel barriers for deep western U.S. Longwall mining. In: Proceedings of the 23rd international conference on ground control in mining. West Virginia University, Morgantown, WV, pp 35-41

Hoelle J (2008) Coal bumps in an Eastern Kentucky coal mine 1989 to 1997. In: Proceedings of the 27th international conference on ground control in mining. West Virginia University, Morgantown, WV, pp 14-19

Holland CT (1958) Cause and occurrence of coal mine bumps. Min Eng, 994-1004B

Holub K (1997) Predisposition to induced seismicity in some Czech coal mines. Pure Appl Geophys 150(3-4):435-450

Holub K, Rušajová J, Holečko J (2011) Particle velocity generated by the rockburst during exploitation of the longwall and its impact on the workings. Int J Rock Mech Min Sci 48(6):942-949

Iannacchione AT, Zelanko JC (1995) Occurrence and remediation of coal mine bursts: a historical review. US Department of the Interior, U.S. Bureau of Mines, Special Publication 01-95, pp 27-68

Iannacchione AT, Varley FD, Brady TM (2008) The application of major hazard risk assessment (MHRA) to eliminate multiple fatality occurrences in the U.S. minerals industry. U.S. Department of Health and Human Services, Centers for Disease Control and Prevention, National Institute for Occupational Safety and Health, Pittsburgh, PA, DHHS (NIOSH) Publication No. 2009B104, IC 9508

Maleki H (1995) An analysis of violent failure in U.S. coal mines: case studies. US Department of the Interior, U.S. Bureau of Mines, Special Publication 01-95, pp 5-26

Maleki H (2006) Caving, seismicity, and mine design in four Utah coal mines. In: Proceedings of the 25th international conference on ground control in mining. West Virginia University, Morgantown, WV, pp 268-276

Maleki H, Zahl EG, Dunford JP (1999) A hybrid statistical-analytical method for assessing violent failure in U.S. coal mines. In: Mark C, Heasley K, Iannacchione A, Tuchman R (eds) Proceedings of the second international workshop on coal pillar mechanics and design. NIOSH, Pittsburgh, pp 139-144
Maleki H, Stewart C, Hunt G (2006) Subsidence characteristics at Bowie Mines, Colorado. In: Proceedings of the golden rocks 2006, 41st US symposium on rock mechanics. American Rock Mechanics Associationm, Alexandria, VA, doc ID 06-932

Maleki H, Stewart C, Stone R, Abshire J (2009) Practical application of numerical modeling for the study of sudden floor heave failure mechanisms. In: Proceedings of the international workshop on numerical modeling for underground mine excavation design. NIOSH, Pittsburgh, PA, pp 89-100

Maleki H, Rigby S, McKenzie J, Faddies T (2011) Historic mine designs and operational practices used in deep mines for controlling coal bumps. In: Proceedings of the 45th US rock mechanics/geomechanics symposium. American Rock Mechanics Association, Alexandria, VA, doc ID 11-276

Mark C, Chase F, Zipf RK, Jr (1997) Preventing massive pillar collapses in coal mines. In: New technology for ground control in retreat mining, NIOSH IC 9446, pp 35-48

Mark C, Phillipson SE, Tyrna P, Gauna M (2012) Characteristics of coal bursts in the North Fork Valley of the Gunnison River, Colorado. In: Proceedings of the 30th international conference on ground control in mining. West Virginia University, Morgantown, WV, pp 1-12

MSHA (1996) Coal mine fatal accident report, fall of face. http:// www.msha.gov/FATALS/1996/FTL96C33.HTM. Accessed 14 Nov 1996

MSHA (2006) Coal mine fatal accident report, fall of face. http://www. msha.gov/FATALS/2006/FTL06c16.asp. Accessed 29 Jan 2006

Mutke G, Stec K (1997) Seismicity in the upper Silesian Coal Basin, Poland: strong regional seismic events. Geophys J Int 168(2):757-768

Pankow K, McCarter M C, Arabasz W, Burlacu R (2008) Coal mining seismicity in Utah-improving spatial resolution using double-difference relocations. In: Proceedings of the 27th international conference on ground control in mining. West Virginia University, Morgantown, WV, pp 91-97

Peperakis J (1958) Mountain bumps at the Sunnyside mines. Min Eng 211:982-986

Potvin Y (2009) Strategies and tactics to control seismic risks in mines. J S Afr Inst Min Metall 109(3):177-186

Rice GS (1935). Bumps in coal mine of the Cumberland Field, Kentucky and Virginia: causes and remedy. US Bureau of Mines RI 3267

Stewart C, Hunt G, Mark C (2006) Geology, ground control and mine planning at Bowie Resources, Paonia, CO. In: Proceedings of the 25th international conference on ground control in mining. West Virginia University, Morgantown, WV, pp 284-290

Swanson P, Stewart C, Koontz W (2008) Monitoring coal mine seismicity with an automated wireless digital strong-motion network. In: Proceedings of the 27th international conference on ground control in mining. West Virginia University, Morgantown, WV, pp 79-86

UUUS (2014) Catalog of coal bursts in Utah, 1981-2013. http://www. seis.utah.edu/EQCENTER/LISTINGS/Catalogs/UT_81.csv

Varley F, Whyatt JK (2008) Work practices to manage bump prone ground. In: Peng SS, Tadolini SC, Mark C, Finfinger GL, Heasley KA, Khair AW, Luo Y (eds) Proceedings of the 27th international conference on ground control in mining. West Virginia University, Morgantown, pp 20-28

Zipf RK (1992) Analysis of stable and unstable pillar failure using a local mine stiffness method. In: Iannacchione A, Mark C, Repsher RC, Tuchman R, Jones CC (eds) Proceedings of the first international workshop on coal pillar mechanics and design. USBM IC 9325, Pittsburgh, PA, pp 128-143 